\title{
Electrocardiographic Findings at Initial Diagnosis in Children with Isolated Left Ventricular Noncompaction
}

\author{
Yakup Ergul, M.D., ${ }^{*}$ Kemal Nisli, M.D., ${ }^{*}$ Muhammet Ali Varkal, M.D., ${ }^{*}$ \\ Naci Oner, M.D., $\dagger$ Memduh Dursun, M.D., $\ddagger$ Aygun Dindar, M.D.,* \\ Umrah Aydogan, M.D., ${ }^{*}$ and Rukiye Eker Omeroglu, M.D.*
}

From the * Department of Pediatric Cardiology, Istanbul Faculty of Medicine, Istanbul University, Istanbul, Turkey; †Kartal Kosuyolu Cardiovascular Research and Training Hospital, Istanbul, Turkey; and $\ddagger$ Department of Radiology, Istanbul Faculty of Medicine, Istanbul University, Istanbul, Turkey

Background: The aim of this study was to comprehensively evaluate electrocardiographic (ECG) findings of isolated left ventricular noncompaction (IVNC) patients at initial diagnosis and to explore the correlation between them and the clinical, echocardiographic, and magnetic resonance imaging (MRI) findings.

Methods: Twenty-three patients diagnosed with IVNC by echocardiography and cardiac MRI between January 2006 and June 2010 were enrolled in this study. The patients were examined with standard ECG and 24-hour Holter ECG. For comparison purpose, ECGs of 50 healthy children of similar ages and demographic characteristics were taken.

Results: In $87 \%$ of patients, ECG abnormalities were found. The most frequently seen ECG findings were left ventricular hypertrophy, ST-segment depression, and negative T wave related to abnormal repolarization particularly in DII, DIII, and $\mathrm{V}_{4-6}$ leads, as well as prolonged PR and QTc intervals. No ECG features or patterns were found that were specific to the disease. In contrast to adult patients, while no intraventricular conduction defects (particularly in the left bundle brach) were found in any of our patients, $13 \%$ had considerable bradycardia and one required a pacemaker. The Holter ECG recordings showed supraventricular tachycardia attacks in two patients and a short ventricular tachycardia attack in one. Patients whose echocardiograms and MRI showed left ventricular systolic dysfunction and left ventricular dilatation had signs of left ventricular hypertrophy and repolarization abnormality on their ECGs, but there was no significant difference in PR, QRS, and QTc intervals.

Conclusion: Regardless of how frequently left ventricular hypertrophy and repolarization abnormalities are found on IVNC patients' initial ECGs, we think that they are not unique to the disease but are related to the severity of the cardiomyopathy.

Ann Noninvasive Electrocardiol 2011;16(2):184-191

left ventricular noncompaction; electrocardiography; children

Left ventricular noncompaction is a primary cardiomyopathy (CMP) that occurs as a result of an arrest in endomyocardial morphogenesis and is characterized by a myocardium consisting of two levels-compacted and noncompacted. ${ }^{1,2}$ Although the rare isolated form of this condition is classified by the American Heart Association as a genetic CMP, in children, it mostly occurs along with other congenital heart diseases. ${ }^{3,4}$ Recent studies show that the disease has been appearing more frequently and now comprises $9 \%$ of all childhood cardiomyopathies. ${ }^{1,5,6}$ While it is the left ventricle that is typically affected, it is reported that the right ventricle can be affected as well. ${ }^{1}$

The clinical signs of patients diagnosed with isolated left ventricular noncompaction (IVNC) vary widely and may occur at any age. Congestive heart failure, thromboembolic events, supraventricular,

Address for correspondence: Yakup Ergul, M.D., Basaksehir Konutlari 5. Etap 1. kisim, D 9 blok, Daire 15 Basaksehir, Istanbul, Turkey. Fax:+90-505-886-08-10; E-mail:yakupergul77@hotmail.com 
and ventricular arrhythmias are the most important clinical features of both child and adult patients. ${ }^{1-3,6-13}$ It is reported that during long-term observations, the rate of ventricular tachycardia (VT) in adults can be as high as $41 \%$, while in children this rate is quite low. ${ }^{2,3,8,14}$

Even though in pediatric researches electrocardiographic (ECG) abnormalities were found in 75$100 \%$ of patients, ${ }^{1,2,8}$ until now the ECG features of pediatric IVNC patients at initial diagnosis have not been systematically analyzed. In our study, we evaluate the ECG findings (at initial diagnosis) of children diagnosed with IVNC via echocardiography and magnetic resonance imaging (MRI); we also examine the contribution of these findings to the diagnosis and the correlation between them and the echocardiography/MRI findings.

\section{METHODS}

In this study, we included 23 patients of ages between 8 days and 16 years who were diagnosed with IVNC in the 4.5-year period between January 2006 and July 2010. Approval for this study was obtained from the ethics committee of the university hospital. All the patients' detailed histories and their physical examination results were recorded, 12-lead ECGs and chest x-rays were taken. All the patients underwent 24-hour Holter ECG monitoring. We did not include those who also had other congenital heart diseases or those who were on digoxin or other antiarrhythmic drugs at the time of admission. In addition to this, a control group was created with 50 healthy child patients of similar age and demographic characteristics, and their 12-lead ECGs were taken as well. The standard and the Holter ECGs recordings were evaluated by two different ECG readers (K.N. and A.D.). With reference values for the pediatric age group ${ }^{15-18}$ taken into account, on each ECG example the following was calculated: heart rate, P-wave height and length, the PR interval, presence of $\mathrm{p}$ mitrale or p pulmonale, QRS length, $\mathrm{R}$ - and S-wave heights in the $\mathrm{V}_{1}, \mathrm{~V}_{2}, \mathrm{~V}_{5}$, or $\mathrm{V}_{6}$ leads (as age-related criteria for left or right ventricular hypertrophy), and lastly, QTc length. By way of comparing the ECG findings of the patient group and the control group to one another and to the age-related reference values, required data were obtained.

All of the patients (100\%) underwent M-mode, two-dimensional (2D) and color Doppler echocardiography and $20(86.9 \%)$ patients underwent a cardiac MRI. Also 50 control patients underwent echocardiography and had normal findings. Echocardiographic assessments were performed according to the recommendations of the American Heart Association, via M-mode and Doppler echocardiography. ${ }^{19,20}$ Trabeculations and deep recesses in the left ventricular myocardium were seen in the parasternal, apical, and subxiphoid axis views. In addition to this, ejection fraction $(\mathrm{EF})$ and contraction fraction $(\mathrm{CF})$ were measured using left ventricular end-systolic and end-diastolic dimensions. The presence of thrombi was investigated. The echocardiographic diagnosis of IVNC ${ }^{21}$ was based on the following: ${ }^{1}$ absense of concomitant cardiac anomalies, ${ }^{2}$ presence of a thin compacted epicardial layer and a thick noncompacted endomyocardial layer with thickening of the left ventricular wall, ${ }^{3}$ the ratio of noncompacted/compacted myocardium at the end of systole being more than two, and ${ }^{4}$ presence of deep intertrabecular recesses communicating with the ventricular cavity and flow in them shown by color Doppler echo (Fig. 1). Echocardiographic examinations were done by three different pediatric cardiologists (K.N., A.D., and U.A.) and the affected segments were recorded. The cardiac MRI was done with a $1.5 \mathrm{~T}$ scanner (Symphony, Siemens Medical Systems, Erlangen, Germany) and those patients whose thick noncompacted myocardium

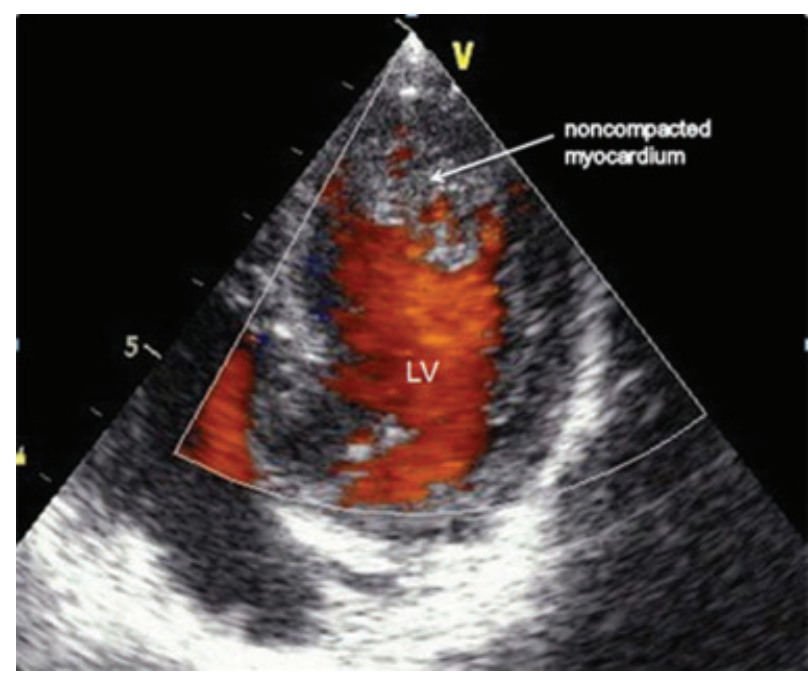

Figure 1. Noncompacted myocardium characterized by a pronounced increase in trabeculation in the left ventricle apex and the free wall on 2D echocardiography, and flow in deep recesses shown by color Doppler ultrasound. 
layer-thin compacted epicardial myocardium layer ratio at the end of diastole was more than 2.3 were diagnosed with IVNC. ${ }^{22}$ During the echocardiographic and cardiac MRI examinations, the myocardium was split into nine segments (one apical, four midventricular, and four basal).

\section{Statistical Analysis}

Statistical Package for the Social Science 13.0 for Windows (SPSS, Inc., Chicago, IL) was used for data analysis (reliability, construct validity, and internal consistency). The average values and intervals were specified as \pm standard deviation (SD). The comparison of categorical variables was performed using the chi-square test and Fisher's exact test (in the case of low sample sizes). Continuous variables were analyzed by two-sided Student's $t$-test for normally distributed variables or the Mann-Whitney U test for nonnormally distributed variables. A P value of $<0.05$ was considered significant. To investigate potential associations, the subgroups were analyzed and correlated according to the ECG, echo, and cardiac MRI findings.

\section{RESULTS}

With the help of echocardiography and cardiac MRI, 23 patients were diagnosed with isolated IVNC: 17 of them $(74 \%)$ were male and six $(26 \%)$ were female. The average age of patients at the time of diagnosis was 4 years ( 8 days -16 years) and the average observation time was $24 \pm 12$ months (6 months-4.5 years). Thirty-six $(72 \%)$ of the patients in the control group were male and $14(28 \%)$ were female and their average age was 4.3 years (6 days-16 years).

\section{Clinical and Chest X-Ray Findings}

The most common clinical sign upon admission was congestive heart failure (seen in eight patients $[34.7 \%])$. The less common ones were cardiomegaly, cyanosis, heart murmurs, weakness, and fatigue. While five patients were admitted with complaints of rhythm disorders, for three of them the actual reason for evaluation was bradycardia. At initial diagnosis and during observation none of the patients developed thromboembolic events, and only one was taking anticoagulants due to having history of intracardiac thrombosis. The examination of chest radiographs showed that $16(69.5 \%)$ patients had cardiomegaly, and in nine of them, the cardiothoracic ratio was over $65 \%$.

\section{ECG Findings}

ECG abnormalities were detected in 20 (87\%) of the 23 patients with isolated IVNC at the time of diagnosis. Table 1 showcases the ECG findings

Table 1. ECG Findings of Patients Diagnosed with Isolated Left Ventricular Noncompaction (IVNC) at the Time of Diagnosis, and Their Comparison to Those of the Control Group (NS: Not Significant)

\begin{tabular}{|c|c|c|c|}
\hline ECG Findings & IVNC Patients $(\mathrm{N}=23)$ & Control Group $(\mathrm{N}=50)$ & P Value \\
\hline Heart rate (beats/minute) & $118 \pm 30$ & $130 \pm 35$ & NS \\
\hline PR interval (ms) & $136 \pm 28$ & $105 \pm 16$ & $<0.001$ \\
\hline QRS duration (ms) & $83 \pm 20$ & $55 \pm 12$ & $<0.001$ \\
\hline $\mathrm{V}_{1} \mathrm{~S}(\mathrm{~mm})$ & $9.5 \pm 5$ & $4.4 \pm 3$ & NS \\
\hline$V_{2} S(m m)$ & $14 \pm 6$ & $9.2 \pm 4.3$ & NS \\
\hline$V_{5} R(\mathrm{~mm})$ & $20.8 \pm 9.7$ & $1.5 \pm 6.2$ & NS \\
\hline $\mathrm{V}_{6} \mathrm{R}(\mathrm{mm})$ & $22.5 \pm 11.5$ & $8.9 \pm 4.6$ & NS \\
\hline $\mathrm{V}_{1} \mathrm{R}(\mathrm{mm})$ & $3.5 \pm 2.3$ & $3.6 \pm 2.3$ & NS \\
\hline $\mathrm{V}_{2} \mathrm{R}(\mathrm{mm})$ & $9.3 \pm 5.5$ & $7.2 \pm 3.4$ & NS \\
\hline $\mathrm{V}_{5} \mathrm{~S}(\mathrm{~mm})$ & $4.4 \pm 4.6$ & $4.4 \pm 3.3$ & NS \\
\hline $\mathrm{V}_{6} \mathrm{~S}(\mathrm{~mm})$ & $2.4 \pm 2$ & $3.3 \pm 2.9$ & NS \\
\hline $\mathrm{V}_{1} \mathrm{~S}+\mathrm{V}_{5} \mathrm{R}(\mathrm{mm})$ & $30.4 \pm 13.6$ & $15.8 \pm 7.9$ & $<0.001$ \\
\hline$V_{2} S+V_{6} R(m m)$ & $36.5 \pm 15.6$ & $18.1 \pm 7.4$ & $<0.001$ \\
\hline$V_{1} R+V_{5} S(m m)$ & $7.8 \pm 6.2$ & $8.1 \pm 4.3$ & NS \\
\hline $\mathrm{V}_{2} \mathrm{R}+\mathrm{V}_{5} \mathrm{~S}(\mathrm{~mm})$ & $11.8 \pm 6.1$ & $10.5 \pm 5.1$ & NS \\
\hline OTc duration (msn) & $449 \pm 24$ & $385 \pm 58$ & $<0.001$ \\
\hline ST segment depression (n) & 10 & 0 & $<0.001$ \\
\hline T-wave inversion (n) & 17 & 2 & $<0.001$ \\
\hline
\end{tabular}


at initial diagnosis and the control group data. In comparison to the control group, in IVNC patients, the PR interval, QRS length, and QT lengths were found to be higher to a statistically significant degree. In addition, the $\mathrm{V}_{1} \mathrm{~S}+\mathrm{V}_{5} \mathrm{R}$ and $\mathrm{V}_{2} \mathrm{~S}+$ $\mathrm{V}_{6} \mathrm{R}$ wave sizes that were used as criteria for left ventricular hypertrophy were larger in the patient group ( $\mathrm{P}<0.001)$. ECGs of IVNC patients were evaluated according to the age group reference values. The most frequent findings were left ventricular hypertrophy $(\mathrm{n}=7,30 \%)$, ST-segment depression $(\mathrm{n}=10,43 \%)$, and negative $\mathrm{T}$ wave $(\mathrm{n}=17$, $74 \%$ ) related to the repolarization abnormality that was seen particularly in the DII, DIII, aVF and $\mathrm{V}_{4-6}$ leads. In 10 patients $(43 \%)$, the QTc interval was longer than the reference value for their age (Figs. 2 and 3). In addition, three patients had atrial dilatation, and in two patients frequent ventricular and supraventricular extrasystoles were detected. The standard and Holter ECGs of one patient showed a Wolf-Parkinson-White (WPW) pattern, and in three patients $(13 \%)$ hemodynamically significant bradycardia was found. During the 24-hour Holter ECG exam, two patients had short supraventricular tachycardia episode (8.7\%), and in one 15-year-old patient who was admitted with complaints of palpitations a 45 beat VT attack was observed. Three patients $(13 \%)$ had completely normal standard and Holter ECGs at the time of diagnosis. During observation one, 2 year 7 month old male patient had sinus node dysfunction, bradycardia (56 bpm average heart rate on the Holter ECG) (Fig. 4), and left ventricular dysfunction (EF 47\%), which necessitated the implantation of a permanent pacemaker. Third and sixth month postprocedure follow-up echocardiograms showed that the ventricular functions had returned to normal.

\section{Echocardiographic and Cardiac MRI Findings}

The 2D echo and cardiac MRI findings of patients with isolated IVNC are shown in Table 2. Examination showed distinct left ventricular trabeculation and intertrabecular recesses communicating with the ventricular cavity in all of the patients. No intracardiac thrombi were found in any of the patients. Despite not being seen on 2D echo, in four $(17 \%)$ patients cardiac MRI revealed that in addition to the left ventricle, the right ventricle apex was also affected. In none of the cases was the right ventricle alone affected. The noncompacted seg- ments of the myocardium were especially obvious on the left ventricular apex $(\mathrm{n}=18,78 \%)$ and in the middle of the posterior ventricle wall. At the time of diagnosis, 16 (69.5\%) patients had left ventricular systolic dysfunction, and $13(56.5 \%)$ had prominent left ventricular dilatation. The ventricular functions of the remaining seven patients $(30.5 \%)$ were normal. The patients' average $\mathrm{EF}$ and $\mathrm{CF}$ were $46 \%$ (18-73) and $23 \%$ (8-38) correspondingly.

When subgroup analysis was made according to clinical symptoms, chest x-rays, ECG, echo, and cardiac MRI findings, the ECGs of the patients who were admitted with heart failure at initial diagnosis and whose cardiothoracic index was more than $65 \%$ showed left ventricular hypertrophy $(\mathrm{P}<0.05)$. Comparing the patients' ECGs to the echo and MRI findings revealed that there was no difference in heart rate, PR, QRS, and QTc times between the patients whose left ventricular EF (LVEF) was $<55 \%$ and $>55 \%$ (P > 0.05). Only in the patients whose ECGs showed left ventricular hypertrophy, LVEF measured with echo was $<55 \%$, and the left ventricular end-diastolic dimension (LVEDD) was above the reference values $(\mathrm{P}=0.037)$. As was expected, in the three patients with normal standard and Holter ECGs, LVEF and LVEDD were normal. In addition to this, none of the patients whose LVEF was less than $30 \%$ had normal ECGs $(\mathrm{P}<0.01)$. When the affected segments were found with the help of echo and MRI and the noncompacted-compacted ratio was evaluated, the patients whose ratio was $>2.5$ and $<2.5$ showed no statistically significant differences on their ECG $(P>0.05)$. Furthermore, we evaluated the ECG findings with respect to which segment of the ventricle was affected, and even though those with an affected apex had a slightly larger sum of $R$ in $V 1$ and $S$ in $V 5$, this was not statistically impor$\operatorname{tant}(\mathrm{P}=0.067)$.

\section{DISCUSSION}

Unlike many pediatric studies of IVNC that have been made to this day, this study concentrates on analyzing the initial ECGs of patients diagnosed with IVNC and on finding correlation between these ECGs and the clinical, echocardiographic, and cardiac MRI findings.

As it has been shown in other conducted studies, ECG abnormalities were found in over $80 \%$ of our patients. The most frequent ECG features we came across were left ventricular hypertrophy, prolonged PR and QTc intervals, ST-segment 


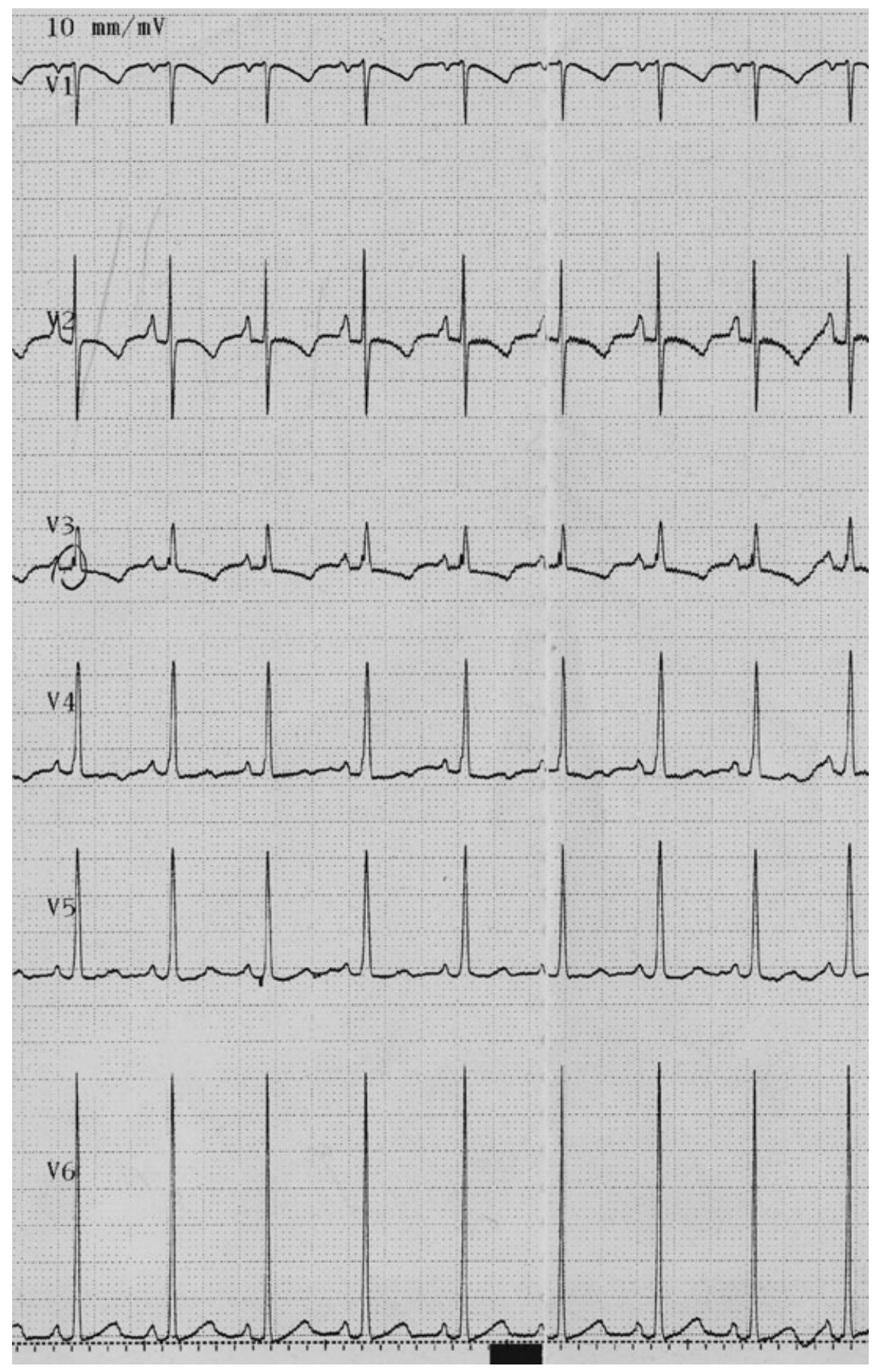

Figure 2. ECG of an 8-day-old newborn admitted with dyspnea and cyanosis and diagnosed with IVNC by echocardiography. Significant left ventricular hypertrophy was seen.

depression, and negative $\mathrm{T}$ wave related to repolarization abnormality. Only three patients had normal ECGs and since none of them had any other complaints other than heart murmurs, the diagno- sis was made after they were admitted and examined. Upon examination of clinical findings, it was determined that the most frequent one upon admission was congestive heart failure. Most of these 


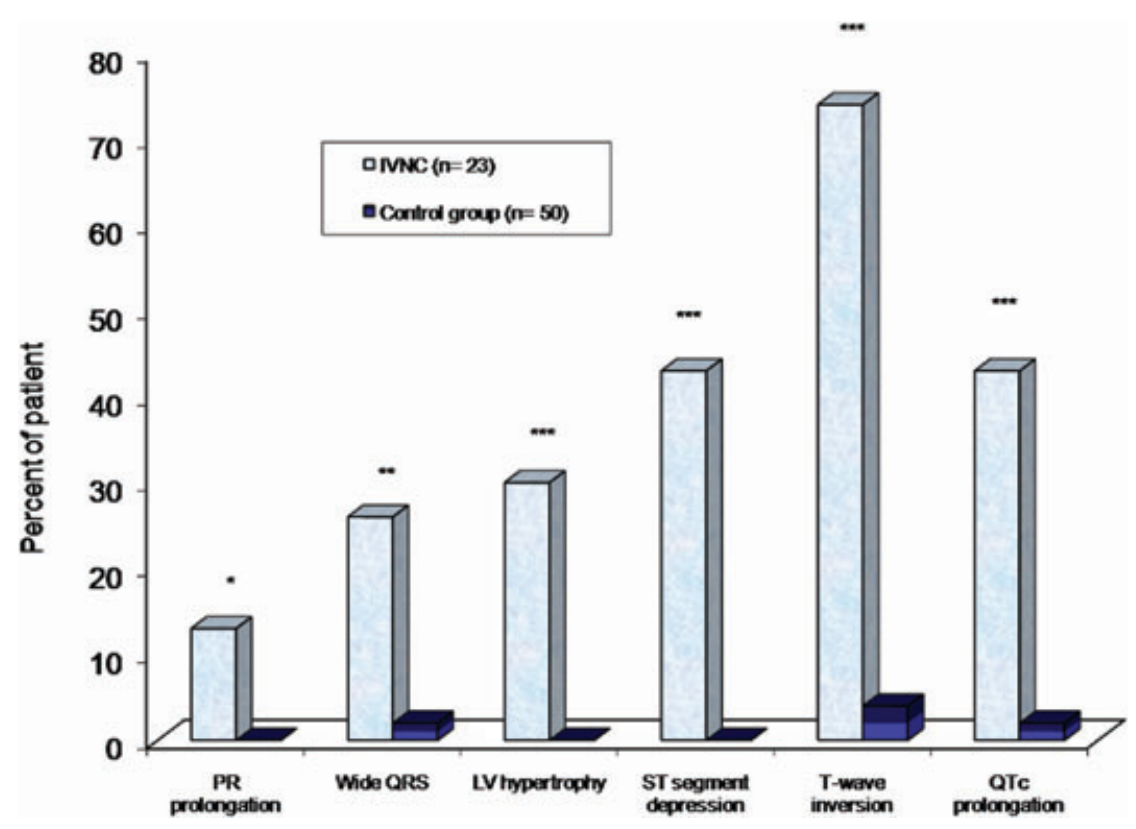

Figure 3. The most frequent ECG findings of IVNC patients at the time of admission. $\left({ }^{*} \mathrm{P}<0.05\right.$; ${ }^{* *} \mathrm{P}<0.01$; $\left.{ }^{* * *} \mathrm{P}<0.001\right)$.

patients' radiographs showed cardiomegaly, and the echocardiograms of a significant portion of patients showed low LVEF and ventricular dilatation. In particular, all of the patients whose LVEF was under $30 \%$ had dilated heart cavities, conduction delays, and also prolonged PR and QTc intervals and slightly wide QRS on their ECGs. Considering these ECG features accompany all severe cardiomyopathies in their advanced stages, ${ }^{22,23}$ it was thought that ECGs abnormalities were unrelated to the disease itself but rather were connected to the severity of the CMP and heart failure. However, unlike adult patient studies, this study showed that despite the QRS interval looking slightly prolonged as compared to the control group, none of the patients had intraventricular conduction delay and notedly, no left bundle branch block (LBBB). Similarly, in the study conducted by Ichida et al., ${ }^{8}$ very few of the patients had LBBB. The difference seen between the child and adult patients supports the idea that ventricular conduction delay could occur later in life and could be the result of endocardial fibrosis. Conversely, as it has been noted in adult patient studies and is generally widely known, at this age left ventricle conduction delay may be caused by the commonly seen systemic hypertension and ischemic heart diseases. ${ }^{8,14,24}$

In our study, ST-segment depression and T-wave inversion due to repolarization abnormality was seen often in the patient group as compared to the control group. The fact that they appear especially in the DII, DIII, aVF and $\mathrm{V}_{4-6}$ leads has led us

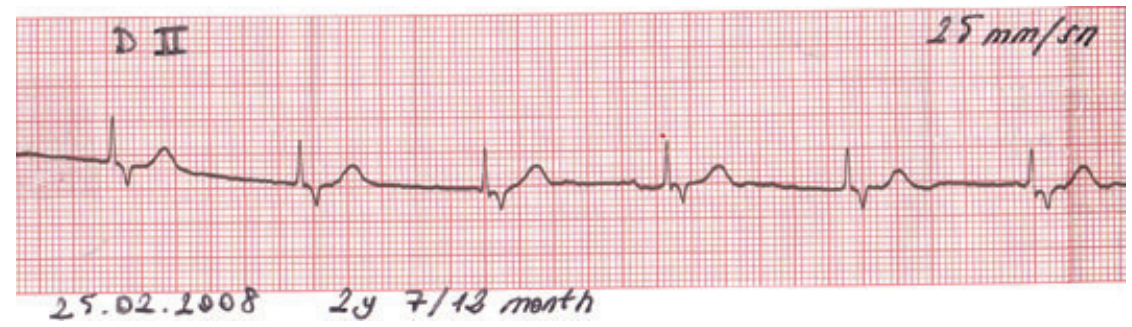

Figure 4. Initial ECG of a $27 / 12$ y.o. male patient who was admitted with bradycardia and sinus node disfunction, diagnosed with IVNC, and implanted with a permanent pacemaker due to left ventricular dysfunction. 
Table 2. Echocardiographic and Cardiac MRI Findings of Patients with Isolated IVNC

\begin{tabular}{|c|c|}
\hline Characteristic & Value (\%) \\
\hline Patients (n) & 23 \\
\hline $\begin{array}{l}\text { Pattern of left ventricular segment } \\
\text { involvement } \\
\text { - Apex } \\
\text { - Midventricular } \\
\text { - Basal }\end{array}$ & $\begin{array}{l}18(78 \%) \\
16(69 \%) \\
2(8.6 \%)\end{array}$ \\
\hline $\begin{array}{l}\text { Right ventricular involvement (with } \\
\text { cardiac MR) }\end{array}$ & $4(17 \%)$ \\
\hline Left ventricular ejection fraction (\%) & 46 \\
\hline $\begin{array}{l}\text { Left ventricular ejection fraction } \\
\qquad<30 \% \\
: 30-55 \% \\
\cdot>55 \%\end{array}$ & $\begin{aligned} & 6(26 \%) \\
& 10(43.5 \%) \\
& 7(30.5 \%)\end{aligned}$ \\
\hline $\begin{array}{l}\text { Left ventricular dilatation } \\
\text { (end-diastolic diameter }>\text { upper limit } \\
\text { of age and weight) }\end{array}$ & $13(56.5 \%)$ \\
\hline
\end{tabular}

to think that they may be related to dysmorphogenesis of the left ventricular myocardium. This thought is supported by the studies of the IVNC pathogenesis, which show that without there being problems with the epicardial coronary arteries, there may be subendocardial microcirculation defects leading to subendocardial ischemia in the noncompacted segments. ${ }^{1,7,24}$ On the other hand, the fact that ECGs show repolarization disorders whenever there is LV dysfunction, whereas patients with normal ECGs have normal LVEFs, has led us to think that these ECG features are not related to the disease but rather could be related to the progression of the CMP.

Potentially fatal arrythmias, such as VT and ventricular fibrillation, are one of the important features of the disease in both children and adults. Studies conducted on adults report that the patients are prone to sudden death, with the VT frequency rate as high as $41-47 \% .^{9,14,24,25}$ While the first pediatric studies by Chin et al. ${ }^{7}$ showed the VT frequency rate to be up to $38 \%$, later studies showed this rate to be no higher than $5 \%,{ }^{1,3,8}$ In our study, this rate was less than $5 \%$. QRS length of over 0.18 seconds creates the risk of monomorphic VT and QTc length of over 0.50 seconds can lead to polymorphic VT attacks; however, despite the QRS-QTc intervals being slightly prolonged as compared to the control group in our study, they were below the aforementioned figures.
While it is widely known that WPW incidence in adults is low, in pediatric studies, it has been suggested that there is a link between IVNC and WPW and the WPW incidence could vary from $0 \%$ to $17 \%^{1,3,7,8,13}$ The continuation of trabeculations in the noncompacted segment in IVNC patients is thought to lead to persistence of myocardial canals between the atrium and the ventricle and to create accessory pathways. ${ }^{26}$ Conversely, in the study by Tsai et al., ${ }^{3}$ WPW was found in three patients (9\%) and in all of them Ebstein's anomaly was found as well. In our study, there was only one patient (4\%) with WPW and his Holter ECG showed no tachyarrythmia.

Bradyarrhythmia is another abnormality that can be seen on the ECGs of patients with isolated IVNC. Studies show that IVNC can be accompanied by severe sinus bradycardia and sinus node dysfunction. ${ }^{12,26,27}$ In our study, $13 \%$ of patients were diagnosed with bradycardia and one required a pacemaker. While the real cause of bradycardia is unknown, it is evident that one must consider IVNC in patients with severe bradycardia and LV dysfunction.

\section{CONCLUSION}

When compared to the control group, the standard ECGs of the patient group clearly show left ventricular hypertrophy, ST-T wave depression related to repolarization abnormality and QTc prolongation. However, these changes are not specific to the disease, but rather are connected to the severity of the CMP. It stands out that intraventricular conduction defects (the main one being LBBB) and ventricular arrhythmias occur less frequently in children, unlike in adult patients. Nevertheless, long-term follow-up is important due to high dysrhythmia rates in these patients.

\section{REFERENCES}

1. Pignatelli RH, McMahon CJ, Dreyer WJ, et al. Clinical characterization of left ventricular noncompaction in children: A relatively common form of cardiomyopathy. Circulation 2003;108:2672-2678.

2. Elshershari H, Okutan V, Celiker A. Isolated noncompaction of ventricular myocardium. Cardiol Young 2001;11: 472-475.

3. Tsai SF, Ebenroth ES, Hurwitz RA, et al. Is left ventricular noncompaction in children truly an isolated lesion? Pediatr Cardiol 2009;30:597-602.

4. Maron BJ, Towbin JA, Thiene G, et al. Contemporary definitions and classification of the cardiomyopathies: An American Heart Association Scientific Statement from the 
Council on Clinical Cardiology, Heart Failure and Transplantation Committee; Quality of Care and Outcomes Research and Functional Genomics and Translational Biology Interdisciplinary Working Groups; and Council on Epidemiology and Prevention. Circulation 2006;113:1807-1816.

5. Nugent AW, Daubeney PE, Chondros P, et al. National Australian Childhood Cardiomyopathy Study. The epidemiology of childhood cardiomyopathy in Australia. N Engl J Med 2003;348:1639-1646.

6. Wald R, Veldtman G, Golding F, et al. Determinants of outcome in isolated ventricular noncompaction in childhood. Am J Cardiol 2004;94:1581-1584.

7. Chin TK, Perloff JK, Williams RG, et al. Isolated noncompaction of left ventricular myocardium: A study of eight cases. Circulation 1990;82:507-513.

8. Ichida F, Hamamichi Y, Miyawaki T, et al. Clinical features of isolated noncompaction of the ventricular myocardium: Long-term clinical course, hemodynamic properties, and genetic background. J Am Coll Cardiol 1999;34:233-240.

9. Oechslin EN, Attenhofer Jost CH, Rojas JR, et al. Long-term follow-up of 34 adults with isolated left ventricular noncompaction: A distinct cardiomyopathy with poor prognosis. J Am Coll Cardiol 2000;36:493-500.

10. Ozkutlu S, Ayabakan C, Celiker A, et al. Noncompaction of ventricular myocardium: A study of twelve patients. J Am Soc Echocardiogr 2002;15:1523-1528.

11. Elshershari $\mathrm{H}$, Okutan $\mathrm{V}$, Celiker A. Isolated noncompaction of ventricular myocardium. Cardiol Young 2001;11:472-475.

12. Celiker A, Ozkutlu S, Dilber E, et al. Rhythm abnormalities in children with isolated ventricular noncompaction. Pacing Clin Electrophysiol 2005;28:1198-1202.

13. Alehan D. Clinical features of isolated left ventricular noncompaction in children. Int J Cardiol 2004;97:233-237.

14. Steffel J, Kobza R, Oechslin E, et al. Electrocardiographic characteristics at initial diagnosis in patients with isolated left ventricular noncompaction. Am J Cardiol 2009;104:984-989.

15. Liebman J. The normal electrocardiogram. In: Liebman J, Plonsey R, Gillette PC (eds.): Pediatric Electrocardiography. Baltimore, Williams \& Wilkins, 1982, pp. 144-171.

16. Park MK. Pediatric Cardiology for Practitioners, 5th Edition. Philadelphia, Mosby Elsevier, 2008, pp. 40-65.
17. Davignon A, Rautaharju P, Boisselle E, et al. Normal ECG standards for infants and children. Pediatr Cardiol 1979;1:123-52.

18. Van Hare GF, Dubin AM. The normal electrocardiogram. In: Allen HD, Driscoll DJ, Shaddy RE, Feltes TF (eds.): Moss and Adam's Heart Disease in Infants, Children and Adolescent, 7th edition. Philedelphia, Lippincott Williams \& Wilkins, 2008, pp. 253-268.

19. Sahn DJ, DeMaria A, Kisslo J, et al. Recommendations regarding quantitation in M-mode echocardiography: Results of a survey of echocardiographic measurements. Circulation 1978;58:1072-1083.

20. Schiller NB, Shah PM, Crawford M, et al. Recommendations for quantitation of the left ventricle by two-dimensional echocardiography. American Society of Echocardiography Committee on Standards, Subcommittee on Quantitation of Two-Dimensional Echocardiograms. J Am Soc Echocardiogr 1989;2:358-367.

21. Jenni R, Oechslin E, Schneider J, et al. Echocardiographic and pathoanatomical characteristics of isolated left ventricular non-compaction: A step towards classification as a distinct cardiomyopathy. Heart 2001;86:666-671.

22. Petersen SE, Selvanayagam JB, Wiesmann F, et al. Left ventricular non-compaction: Insights from cardiovascular magnetic resonance imaging. J Am Coll Cardiol 2005;46: 101-105.

23. Madias JE. The resting electrocardiogram in the management of patients with congestive heart failure: Established applications and new insights. Pacing Clin Electrophysiol 2007;30:123-128.

24. Weiford BC, Subbarao VD, Mulhern KM. Noncompaction of the ventricular myocardium. Circulation 2004;109: 2965-2971.

25. Murphy RT, Thaman R, Blanes JG, et al. Natural history and familial characteristics of isolated left ventricular noncompaction. Eur Heart J 2005;26:187-192.

26. Salerno JC, Chun TU, Rutledge JC. Sinus bradycardia, Wolff Parkinson White, and left ventricular noncompaction: An embryologic connection? Pediatr Cardiol 2008;29:679-682.

27. Ozkutlu S, Onderoglu L, Karagöz T, et al. Isolated noncompaction of left ventricular myocardium with fetal sustained bradycardia due to sick sinus syndrome. Turk J Pediatr 2006;48:383-386. 